\title{
Incidental finding and management of intralobar sequestration of the lung in a 24-year-old man
}

\author{
Dhanjit Litt $\mathrm{MD}^{1 *}$, Sumeet Gandhi $\mathrm{MD}^{1 *}$, Sacha Bhinder $\mathrm{MD}^{2}$, Maurice Blitz $M D^{3}$, Kieran Mclntyre $\mathrm{MD}^{2}$
}

D Litt, S Gandhi, S Bhinder, K McIntyre, M Blitz. Incidental finding and management of intralobar sequestration of the lung in a 24-year-old man. Can Respir J 2013;20(6):403-405.

Pulmonary sequestration is described as a dysplastic mass of lung tissue that lacks communication with the tracheobronchial tree and receives systemic rather than pulmonary arterial blood supply. Two distinct classifications, intralobar and extralobar, have been described. The present article discusses the etiology, clinical and radiographic features of pulmonary sequestration as well as the management of this condition when it is discovered incidentally.

Key Words: Congenital lung conditions; Extralobar sequestration; Intralobar sequestration; Lung bud anomalies

\section{Learning Objectives}

- Review the etiology, clinical and radiographic features of intralobar sequestration (ILS) of the lung.

- Discuss the management of ILS when it is discovered incidentally.

\section{CanMEDS Competency: Medical expert; Manager}

\section{Pretest}

- What is the etiology of ILS of the lung?

- What is the imaging modality of choice to establish a diagnosis of ILS of the lung?

- How should one proceed when ILS of the lung is discovered incidentally?

\section{CASE PRESENTATION}

A 24-year-old man presented to the emergency department with a $48 \mathrm{~h}$ history of abdominal pain. A computed tomography (CT) scan of the abdomen was suggestive of acute appendicitis. Incidentally, cystic dilation of air spaces was noted in a region occupying the right lower lobe. Following appendectomy, the inpatient respirology service was consulted.

His medical history was significant for childhood asthma treated with inhaled corticosteroids and short-acting beta agonists as needed. In the summer of 2011, he was diagnosed with community-acquired pneumonia with consolidation in the right lower lobe on chest $\mathrm{x}$-ray; he was treated with a seven-day course of oral antibiotics as an outpatient, with clinical and radiographic resolution. The patient was a lifelong nonsmoker and worked in the financial sector. Surgical and family histories were noncontributory. Currently, from a cardiorespiratory perspective, the patient was asymptomatic and his functional inquiry was otherwise negative.

On physical examination, a healthy-appearing 24-year-old man was noted. His vital signs were stable and he was afebrile. Aside from bibasilar crackles noted on pulmonary auscultation, physical examination was unremarkable.

\section{La découverte fortuite et la prise en charge d'une séquestration pulmonaire intralobaire chez un homme de 24 ans}

La séquestration pulmonaire désigne une masse dysplasique des tissus pulmonaires qui ne communique pas avec l'arbre trachéobronchique et qui reçoit du sang artériel systémique plutôt que pulmonaire. On lui a déjà attribué deux classifications, intralobaire et extralobaire. Le présent article expose l'étiologie et les caractéristiques cliniques et radiographiques de la séquestration pulmonaire, de même que la prise en charge de ce problème lorsqu'on le découvre de façon fortuite.

Contrast-enhanced CT angiography of the thorax confirmed the presence of a lesion containing dilated airspaces occupying the posterior basal segment of the right lower lobe (Figure 1). Arterial supply to the lesion was derived from the celiac artery (Figures 2A and 2B) and venous drainage was via the inferior pulmonary vein. There was no communication between the lesion and the remainder of the tracheobronchial tree. With these findings, a diagnosis of ILS of the lung was made.

After consultation with thoracic surgery, arrangements were made for resection via video-assisted thoracic surgery. During the procedure, the presence of an aberrant artery arising from the subdiaphragmatic aorta was confirmed. After successful division of the feeding vessel, resection of the right lower lobe was performed. Intraoperative blood loss was minimal and there were no postoperative complications. The patient was discharged home on postoperative day 3 .

The resected specimen revealed an affected area of fibrotic and hemorrhagic tissue located inferiorly in the right lower lobe. The lesion measured $7.5 \mathrm{~cm} \times 5.0 \mathrm{~cm} \times 5.0 \mathrm{~cm}$ and extended to the pleural surface, where a ragged appearance with fibrous adhesions was noted. Microscopically, a well-demarcated area of cystically dilated bronchoalveolar spaces lined by ciliated respiratory epithelium with a scant lymphocytic stromal infiltrate was observed (Figure 3). The surrounding parenchyma on both gross and histological examination was normal. Collectively, these findings supported the diagnosis of ILS.

\section{DISCUSSION}

Pulmonary sequestration was first described by Huber in 1777. It is characterized as a dysplastic mass of lung tissue that lacks communication with the tracheobronchial tree and receives systemic rather than pulmonary arterial blood supply (1). Pulmonary sequestration can be further classified into two distinct types: intralobar and extralobar. These differ based on clinical features, location, pleural covering and venous drainage (Table 1). Pulmonary sequestration is a rare condition and is encountered at a rate of less than one case per year at tertiary referral centres (2).

The etiology of ILS is unclear, with evidence equally supporting both acquired and congenital hypotheses. The latter is well described

*Co-first authors

${ }^{1}$ Department of Medicine, Division of Internal Medicine, University of Toronto; ${ }^{2}$ Department of Medicine, Division of Respirology, St Michael's

Hospital; ${ }^{3}$ Department of Surgery, Division of Thoracic Surgery, University of Toronto, Toronto, Ontario

Correspondence: Dr Kieran McIntyre, Division of Respirology, University of Toronto, St Michael's Hospital, Room 6-037, 30 Bond Street,

Toronto, Ontario M5B 1W8. Telephone 416-864-6206, fax 416-864-5649, e-mail mcintyrek@smh.ca 


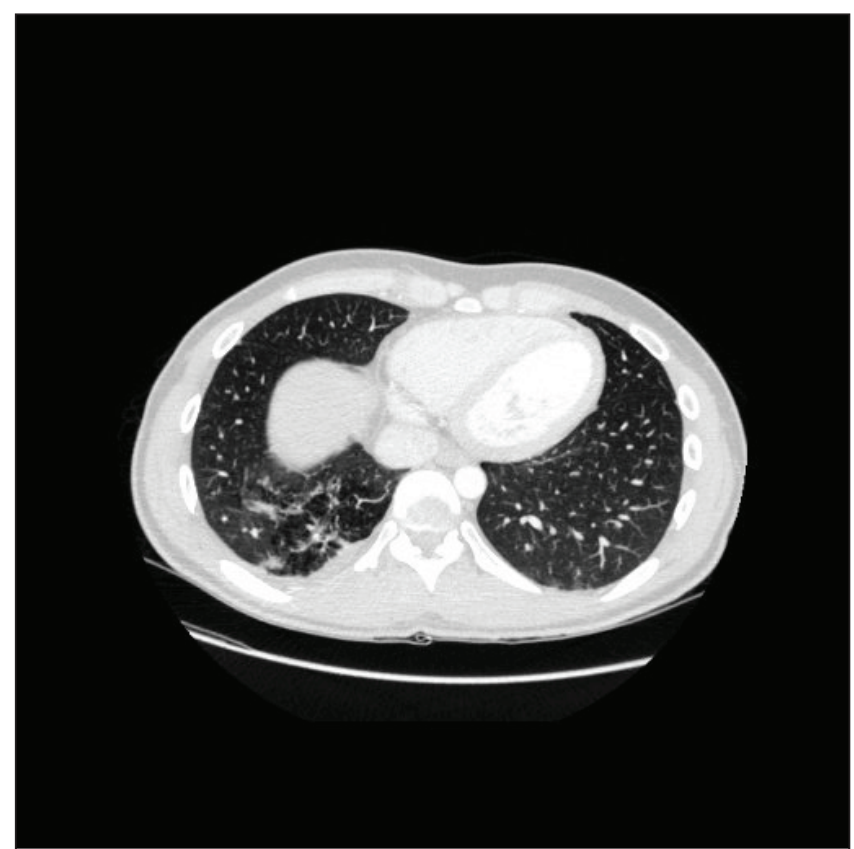

Figure 1) Contrast-enhanced thoracic computed tomography angiography. Transverse section showing cystic dilation of airspaces in a region occupying the right lower lobe

by Pryce (1), who proposed that ILS occurs as a result of either the formation of an accessory lung bud or due to the capture and subsequent traction of a tip of the developing lung by a systemic artery. An alternative explanation was later offered by Smith (3), who proposed that the initial defect was in the primitive pulmonary arterial supply. According to Smith (3), a lack of blood flow to the developing lung leads to the retention of vessels from the primitive dorsal aorta, and exposure to systemic arterial pressure after birth leads to the changes observed. Recently, the observation that ILS is more commonly encountered in adults and that coexisting congenital anomalies in this condition are rare has lead to the proposal that ILS is an acquired phenomenon. Although the details are yet to be established, it has been suggested that an unknown trigger serves as a stimulus for the development of an aberrant systemic arterial supply in late childhood or early adulthood (4).

The key to establishing the diagnosis of ILS lies in identifying the aberrant arterial supply. Both CT and magnetic resonance imaging have proven to be effective in this regard. However, multidetector CT angiography is emerging as the diagnostic test of choice because it is better able to simultaneously visualize and provide details of the arterial supply, lung parenchyma and venous drainage (5-7).

Classically, ILS in adults has been identified in the work-up for recurrent lower respiratory tract infections (2). Our patient was once previously treated for right lower lobe pneumonia and this was, in fact, very likely an infection of the sequestrum. However, the diagnosis of ILS in the present case was made incidentally, during imaging for a completely unrelated condition. We found that current guidelines did not offer recommendations for management in this case.

Traditionally, as a preventive measure or as a treatment option for recurrent pneumonia, most centres recommend early surgical resection (8). Potentially adding further support for early resection are recent case reports that describe more severe complications such as life-threatening hemorrhage and malignant transformation $(9,10)$. However, it is important to note that in the largest case series on ILS published to date, a large percentage of patients were asymptomatic (2). Also, although it would be difficult to study, it is possible that the number of patients with undiagnosed ILS is greater than those who develop symptoms. Finally, although severe complications, such as malignant transformation, have been documented in case reports,
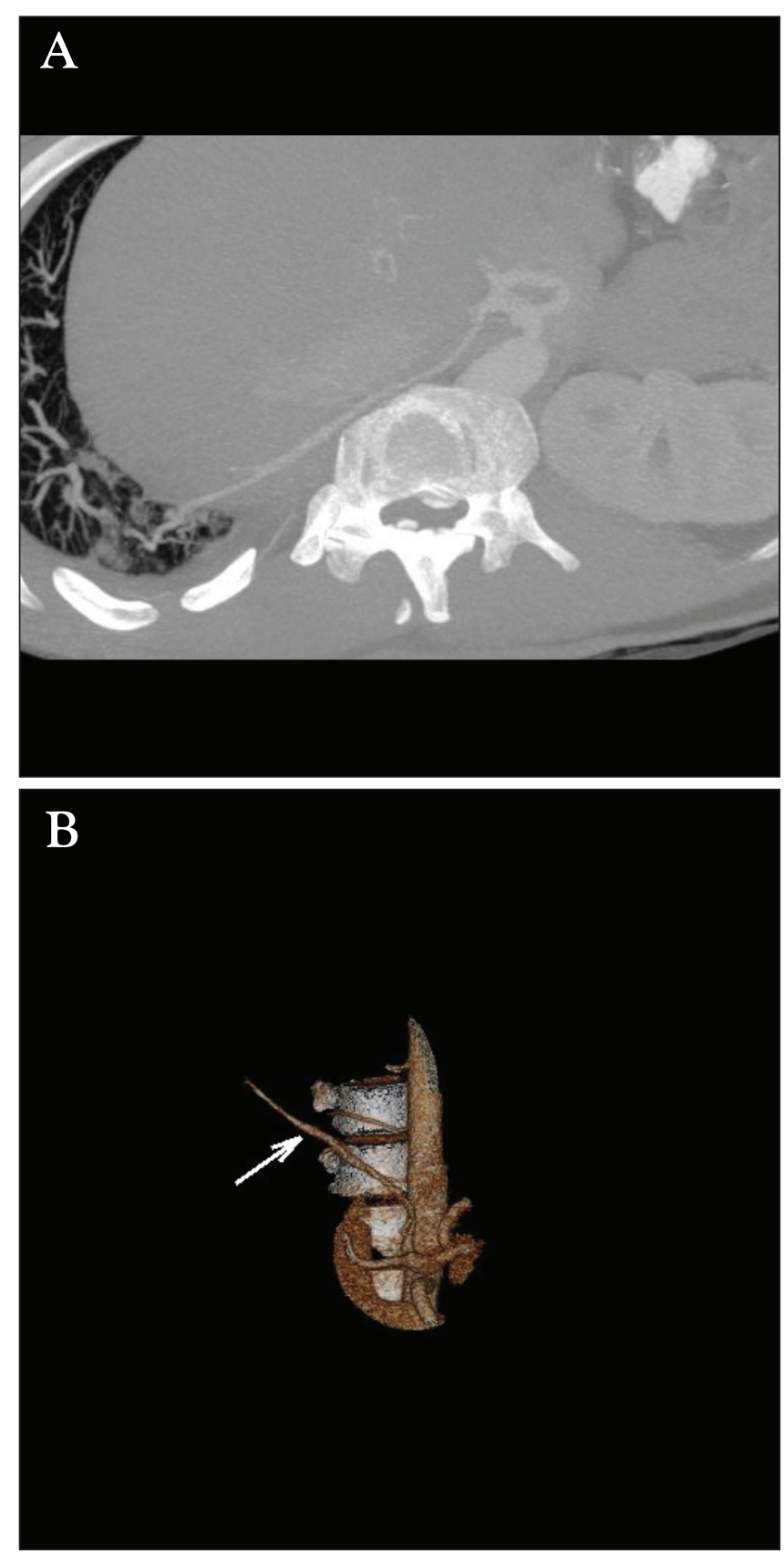

Figure 2) A Contrast-enhanced thoracic computed tomography angiography. Transverse section: multiplanar reconstructive image showing a vessel arising from the abdominal aorta entering the right lower lobe. B Contrast-enhanced thoracic computed tomography angiography. Threedimensional reconstructive image showing that the aberrant vessel is a branch of the celiac artery (arrow)

we should remain cognizant of the fact that these are extremely rare occurrences.

Given that the patient was currently asymptomatic, with only one previously documented lower respiratory tract infection, we presented two management options to him: close follow-up with surgical resection should he become symptomatic versus immediate preventive resection. The patient opted for the latter.

\section{CONCLUSION}

ILS is a rare congenital lung anomaly that can present in adulthood. As advanced imaging modalities become more routine and available, the diagnosis of ILS as an incidental finding will likely become more 


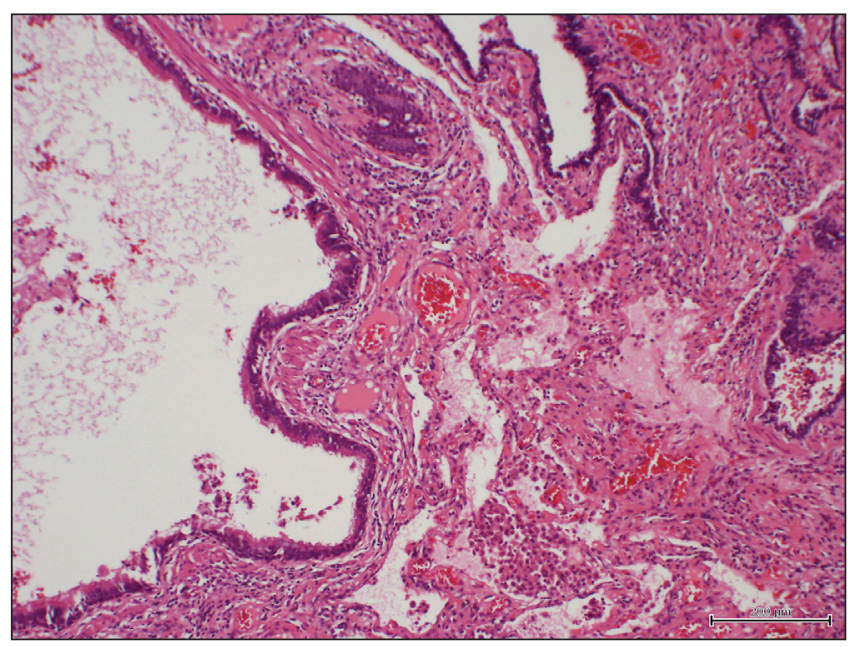

Figure 3) Intralobar sequestration consisting of a cystically dilated airspace (left) lined by normal respiratory epithelium with a lymphocytic stromal infiltrate. Hematoxylin and eosin stain, medium-power magnification

common. Although most centres recommend early resection, given that many patients remain asymptomatic and that severe complications are rare, close outpatient follow-up may be a reasonable management option for patients with ILS discovered incidentally. In the absence of established guidelines, the decision to proceed with resection should be made with the patient on a case-by-case basis when ILS is discovered incidentally.

\section{Post-test}

- What is the etiology of ILS of the lung?

The exact etiology of ILS is uncertain. There is evidence supporting both acquired and congenital hypotheses.

- What is the imaging modality of choice to establish a diagnosis of ILS of the lung?

Both magnetic resonance imaging and CT are effective in identifying that aberrant arterial supply and, thus, establishing the diagnosis of ILS. However, given its ability to better simultaneously visualize the arterial supply, pulmonary parenchyma and venous drainage, multidetector CT angiography is emerging as the diagnostic test of choice.

- How should one proceed when ILS of the lung is discovered incidentally?

Current guidelines offer no recommendations regarding how to proceed with incidental ILS. Most centres perform early surgical resection on all cases of ILS. However, given that many patients remain asymptomatic and that severe complications are rare, close outpatient follow-up may be a reasonable management option when ILS is discovered incidentally.
TABLE 1

Comparison of the anatomical and clinical features of intralobar and extralobar sequestration

\begin{tabular}{|c|c|c|}
\hline & \multicolumn{2}{|c|}{ Sequestration } \\
\hline & Intralobar & Extralobar \\
\hline Arterial supply & Systemic & Systemic \\
\hline Venous drainage & Pulmonary venous system & Systemic venous system \\
\hline Location & Within normal lung & Outside of normal lung \\
\hline Pleura & Shared & Invested in own pleura \\
\hline Clinical features & $\begin{array}{l}\text { Commonly present in late } \\
\text { childhood/early adulthood } \\
\text { with recurrent lower } \\
\text { respiratory tract infection } \\
\text { Coexisting congenital } \\
\text { anomalies are less } \\
\text { common }\end{array}$ & $\begin{array}{l}\text { More likely to present in } \\
\text { neonates and young } \\
\text { children } \\
\text { Coexisting congenital } \\
\text { anomalies are more } \\
\text { common }\end{array}$ \\
\hline
\end{tabular}

\section{REFERENCES}

1. Pryce DM. Lower accessory pulmonary artery with intralobar sequestration of lung; a report of seven cases. J Pathol Bacteriol 1946;58:457-67.

2. Savic B, Birtel FJ, Tholen W, Funke HD, Knoche R. Lung sequestration: Report of seven cases and review of 540 published cases. Thorax 1979;34:96-101.

3. Smith RA. A theory of the origin of intralobar sequestration of lung. Thorax 1956;11:10-24.

4. Holder PD, Langston C. Intralobar pulmonary sequestration (a nonentity?). Pediatr Pulmonol 1986;2:147-53.

5. Ko SF, Ng SH, Lee TY, et al. Noninvasive imaging of bronchopulmonary sequestration. AJR Am J Roentgenol 2000;175:1005-12.

6. Ikezoe J, Murayama S, Godwin JD, Done SL, Verschakelen JA. Bronchopulmonary sequestration: CT assessment. Radiology 1990;176:375-9.

7. Kang M, Khandelwal N, Ojili V, Rao KL, Rana SS. Multidetector CT angiography in pulmonary sequestration. J Comput Assist Tomogr 2006;30:926-32.

8. Van Raemdonck D, De Boeck K, Devlieger H, et al. Pulmonary sequestration: A comparison between pediatric and adult patients. Eur J Cardiothorac Surg 2001;19:388-95

9. Lawal L, Mikroulis D, Eleftheriadis S, Karros P, Bougioukas I, Bougioukas G. Adenocarcinoma in pulmonary sequestration. Asian Cardiovasc Thorac Ann 2011;19:433-5.

10. Yoshitake S, Hayashi H, Osada H, Kawahara M. Emergency laparotomy helped the resection of an intralobar pulmonary sequestration with haemorrhagic shock. Eur J Cardiothorac Surg 2013;43:190-2. 


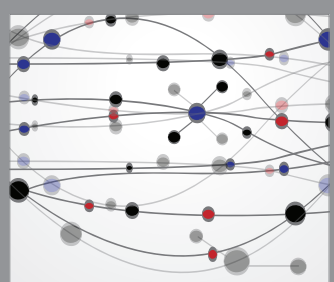

The Scientific World Journal
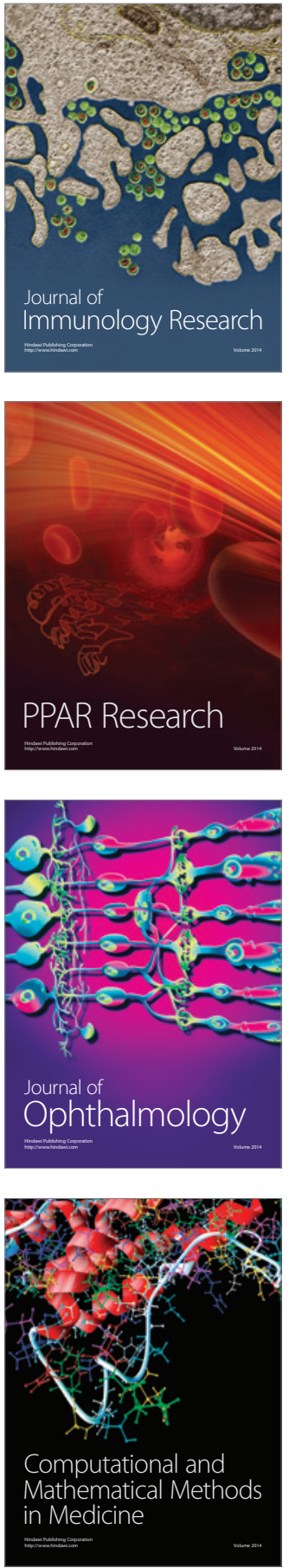

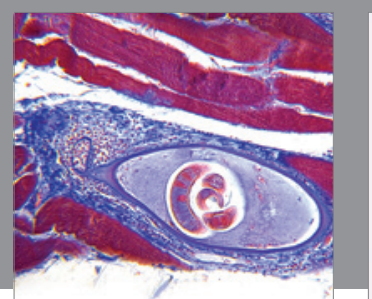

Gastroenterology Research and Practice

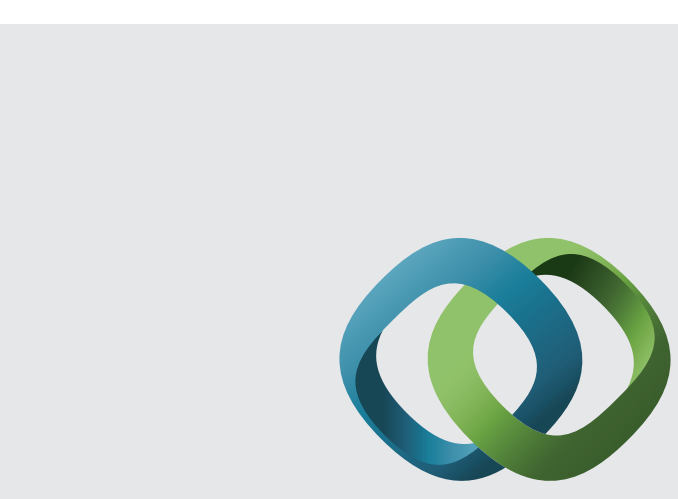

\section{Hindawi}

Submit your manuscripts at

http://www.hindawi.com
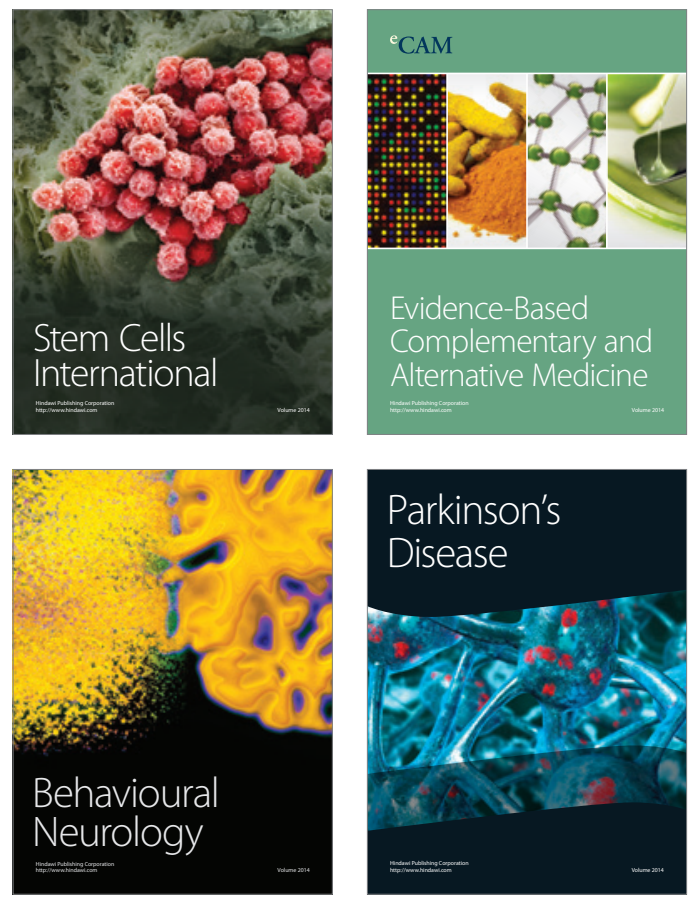
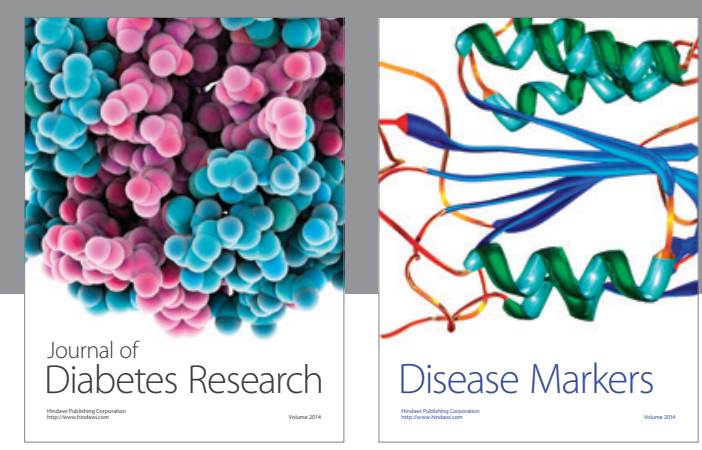

Disease Markers
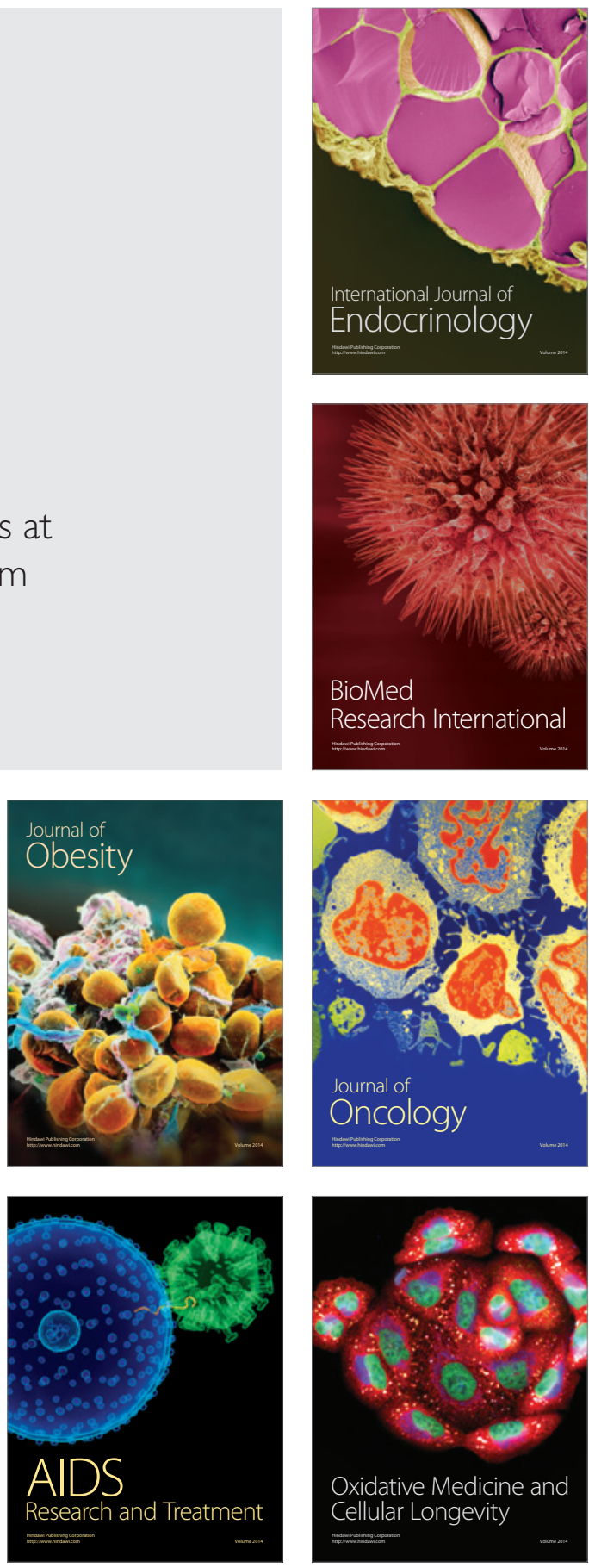